I Universidade de São Paulo (USP), Programa de Pós-Graduação

em Antropologia Social, São Paulo, SP, Brasil

luciaks@gmail.com

\title{
IMAGENS POLÍTICAS E A POLÍTICA DAS IMAGENS
}

Alonso, Angela \& Espada, Heloisa (orgs). (2017).

Conflitos: fotografia e violência política no Brasil, I889-1964.

São Paulo: IMS, 427 p.

Há histórias feitas a partir de imagens e há imagens que fazem história. A sentença que em um primeiro momento pode soar tautológica expressa, na verdade, uma questão conceitual de fundo. O lugar reservado às fontes imagéticas na pesquisa historiográfica é matéria polêmica e de rendimento antigo (ver, entre outros, Knauss, 2006). Jacques Rancière (20I2) faz o alerta sobre a necessidade de as imagens serem compreendidas em sua alteridade, evitando o gesto fácil de as reduzir a sua simples visualidade, a seu sentido de representação. Para o filósofo, a política das imagens só pode ser percebida na suspensão do sentido narrativo entre a intenção do produtor e a recepção do espectador. A eficácia estética da imagem, portanto, não reside no conteúdo político da mensagem, mas sim na articulação entre seus elementos e funções ativados em sua circulação social.

A reflexão de Rancière mostra-se bastante produtiva frente à leitura do catálogo Conflitos: fotografia e violência política no Brasil, I 889- I 964, lançado por ocasião da exposição de mesmo nome promovida pelo Instituto Moreira Sales (IMS). ${ }^{\mathrm{I}} \mathrm{A}$ exposição tem como parti pris desconstruir a narrativa histórica do Brasil como país pacífico, de povo ordeiro, a partir da apresentação de imagens de 18 conflitos civis envolvendo o Estado e as Forças Armadas no curto período entre o nascimento da República e o golpe militar de i964. Organizado pela curadora da exposição, Heloisa Espada, com a socióloga e professora da USP Angela Alonso, o livro reproduz cerca de 300 fotografias que compõem a mostra, intercaladas por textos de especialistas. 
Na dupla apresentação, assinada por uma e outra organizadora, já é possível entrever os diferentes pontos de vista dedicados ao objeto em análise. Estabelece-se uma dicotomia que percorrerá todo o catálogo entre uma história escrita sobre e a partir das imagens e uma história tout court, que contextualiza a produção das fotografias sem lhes dar, entretanto, a prerrogativa de fontes autônomas. Tal contraste não é por si negativo. O que o torna nesse caso problemático é a hierarquização do argumento, que dá a prerrogativa de narrativa histórica aos textos que abordam as imagens como mero suporte, em detrimento daqueles que produzem conhecimento a partir das fontes imagéticas, especialmente em se tratando do catálogo de uma exposição fotográfica.

Heloisa Espada apresenta a mostra como um ponto de inflexão na história da fotografia no Brasil, marcada sobretudo por representações icônicas, a partir da exibição de fragmentos de uma história de disputas políticas e armas (p. 7). A curadora traça, então, uma vis ta panorâmica da história da fotografia e do fotojornalismo no país, pontuada pelas disputas políticas registradas pelas lentes de profissionais e amadores. Destacando que "toda imagem realizada num conflito é interessada", Espada indica seu intento de discutir não apenas os registros imagéticos em si, mas o papel reservado à fotografia em cada um desses conflitos.

Angela Alonso dedica-se a apresentar a premissa política que sustenta o mote da exposição, qual seja, demonstrar que a imagem construída do Brasil como país pacífico e de povo conciliador é falsa. E passa, então, a discorrer sobre o contexto histórico dos conflitos retratados, que caracteriza com muita propriedade como disputas marcadas por questões de classe, em que ora as elites emergem disputando a condução do Estado, ora o povo se insubordina na luta por direitos. Quando destaca a luta simbólica por trás das disputas políticas, a guerra lexical parece ser o que mais interessa à socióloga (p. 20). Ao tratar do papel da tecnologia, em pleno desenvolvimento no início do século XX, Alonso reforça os avanços propiciados por invenções como o telégrafo, a locomotiva ou mesmo o canhão, sem se referir, porém, àquelas que propiciaram a propagação da imagem na modernidade (p. 27).

Assim como a exposição, o catálogo é dividido cronologicamente em três momentos, a saber: A República da degola (I889-I9I6); A República dos bombardeios (I923-I935); As ruas da República (I954-I964). Angela Alonso, Ângela de Castro Gomes e Heloísa Murgel Starling assinam, respectivamente, os textos que introduzem cada um desses períodos históricos, contextualizando os conflitos que serão mostrados. As três pesquisadoras são sensíveis ao poder das imagens na construção da memória histórica. Os títulos dos capítulos emanam uma potência imagética que se evidencia nas fotografias que os seguem. No decorrer dos textos, porém, a referência à fotografia, objeto central da análise em Conflitos, quase desaparece. Subordinadas a outras fontes, são por mais das vezes tratadas como produto da realidade em detrimento de serem 
reconhecidas como produtoras desta (Schwarcz, 20I4).

Os sete ensaios voltados para a investigação de fontes imagéticas são o ponto alto do livro. Autores oriundos de áreas diversas, como museologia, história da arte, cultura visual, e com metodologias de análise imagética distintas compõem um painel multidisciplinar bastante rico. As páginas de abertura desses artigos são ilustradas pelo detalhe ampliado de uma das fotos analisadas, diferenciando-os dos demais textos e destacando para o leitor o conteúdo do estudo. Deixando que a fotografia fale por si, as análises sempre seguem o caderno de imagens ao qual se referem, dando assim precedência às imagens na dinâmica da leitura.

As fotografias realizadas por Flávio de Barros durante a campanha de Canudos foram objeto da pesquisa de mestrado de Cícero Antônio de Almeida, defendida em I999, e aqui apresentada de forma resumida. Almeida infere a partir das fotografias uma série de dados históricos que não se deixaram perceber por outras fontes. É assim, por exemplo, que o autor identifica o provável responsável pela contratação do fotógrafo. Flávio de Barros foi a Canudos com a missão de documentar o conflito para o Exército. Subvertendo a intencionalidade oficial do registro, Almeida demonstra que, na historiografia do evento, as fotografias de Barros foram decisivas para dar voz e rosto aos seguidores de Antônio Conselheiro (p. 84).

Ao cotejar dois conjuntos fotográficos sobre a guerra do Contestado, um álbum organizado pelo Exército e outro uma iniciativa particular do fotógrafo
Claro Jansson, Rogério Rosa Rodrigues reconstitui a história do evento bélico tendo como linha de condução as imagens. Rodrigues produz algumas das mais inspiradas análises imagéticas presentes no catálogo. A partir de um personagem peculiar do conflito, Henrique Wolland, chamado Alemãosinho, o autor destaca a agência dos retratados, aquilo que foge ao controle de quem dispara a câmera. Alemãosinho escolheu como e quando se fazer registrar, sendo o único civil revoltoso a aparecer no álbum do Exército em posição de igualdade com os oficiais (p. I3I). A mesma agência teve um menino, anônimo, que se tornou protagonista de um retrato de grupo produzido por Claro Jansson. A fotografia, criada para ser um monumento histórico sobre o conflito, reúne militares, civis, rebeldes rendidos em pose medida. O menino negro empoleirado nos galhos de uma árvore desponta sobre a cabeça dos demais, tornando-se um incontornável destaque (p. I28).

Ana Maria Mauad, ao discorrer sobre a cobertura dos conflitos de I930 e I932 pelas revistas ilustradas, traz à tona questões transversais à análise e que, até então, não haviam sido destacadas. Quando trata da constituição de uma identidade do povo brasileiro, essencialmente mestiço, forjada pelas imagens nas primeiras décadas do século $\mathrm{XX}$, a autora ressalta a ausência de mulheres e crianças nessa iconografia ( $p$. 268). Os arquivos históricos não são neutros, como sabemos. Mauad politiza a natureza dos acervos imagéticos mobilizados na pesquisa quando aponta a censura operada nos veículos de comu- 
nicação, que divulgavam uma visão unificada dos acontecimentos (p. 270).

Ressente-se a falta de uma análise histórica transversal - e não apenas estudos de caso - que tivesse como fonte principal os documentos imagéticos. Levar a cabo o entendimento das imagens como fontes autônomas e sua imanência histórica permitiria, por exemplo, trazer à tona diálogos formais que muitas vezes se sobrepõem à conjuntura. Como afirma E. H. Gombrich (2007), uma imagem deve muito mais a outras imagens - ao repertório imagético conhecido - do que ao contexto de sua realização, devido às convenções e esquemas visuais criados pela humanidade ao longo dos séculos. As imagens ultrapassam o factual por sua força expressiva. Ou, nas palavras de Kossoy, "Um conhecimento que parte da superfície iconográfica tanto mais nos revela quanto mais buscamos sua realidade interior" (Kossoy \& Schwarcz, 20 I 2: 23).

Ainda que em vários textos do catálogo sejam feitas referências históricas a eventos bélicos e insurgencionais anteriores aos aqui retratados, as convenções imagéticas presentes em muitas das fotografias não foram destacadas. As imagens de barricadas fechando ruas compõem o imaginário coletivo de sublevação ao menos desde os daguerreótipos de Thibaut retratando uma Paris sitiada em I848. São eles que ecoam nas imagens de José Greco documentando a Revolução Federalista de 1893 (p. 49-50) e de Gustavo Prugner quando retrata São Paulo durante a Revolução de 1924 (p. I87-I88). A opção de enquadramento das fotos de igrejas destruídas por tiros e bombas feitas por Flávio de Barros em Canudos (p. 76-77) remetem à imagem das ruínas da igreja de Humaitá por consequência da Guerra do Paraguai, que tanto circulou no Brasil em forma de cartão-postal no período imediatamente posterior ao conflito. E poderíamos fazer seguir a esses exemplos uma série de outros que demonstram a força das convenções imagéticas na construção fotográfica dos conflitos aqui evidenciados.

Quando consideradas enquanto fontes de conhecimento, as imagens podem ser muito mais polissêmicas do que os textos (Löwy, 2009: I6). A montagem da exposição se encerra não com uma imagem, mas com a reprodução sonora do depoimento do comunista Gregório Bezerra, preso e torturado durante o governo militar instaurado pelo golpe de I964. Tal opção, defendida pelo argumento de que "a brutalidade do que é narrado dispensa imagens" (p. I5), demonstra-se nesse caso bastante reveladora.

Assim como a exposição, o catálogo é voltado para um público amplo, mais do que para o debate especializado. Nesse sentido, mostra-se um livro indispensável pelo conjunto de imagens históricas que reúne e pela pertinência e atualidade dos textos apresentados. Seu lançamento não podia ser mais oportuno. O tempo presente está marcado por crises políticas e humanitárias. Esse cenário de incertezas, aliado à ascendência da imagem como linguagem, tem animado exposições artísticas recentes. ${ }^{2}$ As fotografias aqui apresenta- 
das desvelam o passado como sedimento vivo, formador de uma memória que, por se construir no presente, deve ser permanentemente reconfigurada. Retomando a reflexão de Rancière, fez-se um brilhante esforço de reunião de imagens políticas sobre o passado recente do Brasil. Poder-se-ia ter feito mais para trazer à tona a política dessas imagens.

Recebida em I3/4/2018 Revista em 24/4/2018 Aprovada 25/4/2018

Lucia Klück Stumpf é doutoranda do Programa de Pós-Graduação em Antropologia Social da USP, onde desenvolve pesquisa sobre arte, raça e circulações imagéticas no século XIX, com estágio-sanduíche realizado no Global History Department, Princeton University. Mestre em Culturas e Identidades Brasileiras pelo IEB/USP, com pesquisa sobre a pintura de história de Antônio Parreiras (I 860-I926) durante a Primeira República no Brasil. Co-autora, com Lilia Schwarcz, do livro A Batalha do Avaí: a beleza da barbárie (2013). 


\section{NOTAS}

I Conflitos: fotografia e violência política no Brasil I889-I964. Curadoria de Heloisa Espada. Instituto Moreira Sales: Rio de Janeiro, nov. 2017-fev. 2018; São Paulo, maio-jun. 2018.

2

Duas mostras separadas por um ano entre suas inaugurações e que no Brasil tiveram exibição simultânea encontram eco no título e no intuito de associar estética e política para provocar reflexões sobre o presente. Refiro-me às exposições Levantes (Soulèvements), com curadoria de Didi-Huberman (Jeu de Paume, Paris, out. 20I6-jan. 2017. São Paulo, Sesc-Pinheiros, out. 2017-jan. 2018), e Conflitos, organizada por Heloísa Espada, cujo catálogo é aqui analisado.

\section{REFERÊNCIAS BIBLIOGRÁFICAS}

Didi-Huberman, Georges (org.). (20I7). Levantes. São Paulo: Edições Sesc.

Gombrich, Ernst Hans. (2007). Arte e ilusão. São Paulo: Martins Fontes.

Knauss, Paulo. (2006). O desafio de fazer história com imagens: arte e cultura visual. ArtCultura, Uberlândia, 8/I2, p. 97-II5.

Kossoy, Boris \& Schwarcz, Lilia. (20I2). Um olhar sobre o Brasil. A fotografia na construção da imagem da nação I883-2003. Rio de Janeiro: Objetiva.

Löwy, Michael (org.). (2009). Revoluções. São Paulo: Boitempo.

Rancière, Jacques. (20I2). O destino das imagens. São Paulo: Contraponto. Schwarcz, Lilia M. (20I4). Lendo e agenciando imagens: o rei, a natureza e seus belos naturais. Sociologia e Antropologia, Rio de Janeiro, 4/2, p. 39I-43I. 